\title{
Should Immediate Autologous Breast Reconstruction be considered in Women who require Post-Mastectomy Radiation Therapy? A Prospective Analysis of Outcomes
}

\author{
Jessica Billig, MD¹, Reshma Jagsi, MD DPhil ${ }^{2}$, Ji Qi, MS ${ }^{1}$, Jennifer B. Hamill, MPH ${ }^{1}$, \\ Hyungjin M. Kim, ScD ${ }^{3}$, Andrea L. Pusic, MD MHS ${ }^{4}$, Edward Buchel, MD ${ }^{5}$, Edwin G. Wilkins, \\ MD MS ${ }^{1}$, and Adeyiza O. Momoh, MD ${ }^{1}$ \\ ${ }^{1}$ Section of Plastic Surgery, University of Michigan, Ann Arbor, MI \\ ${ }^{2}$ Department of Radiation Oncology, University of Michigan, Ann Arbor, MI \\ ${ }^{3}$ Department of Biostatistics, University of Michigan, Ann Arbor, MI \\ ${ }^{4}$ Division of Plastic and Reconstructive Surgery, Memorial Sloan-Kettering Cancer Center, New \\ York, NY \\ ${ }^{5}$ Section of Plastic Surgery, University of Manitoba, Winnipeg, Manitoba
}

\section{Abstract}

\begin{abstract}
Background-In women who require post-mastectomy radiation therapy, immediate autologous breast reconstruction is often discouraged. We aim to prospectively evaluate postoperative morbidity and satisfaction reported by women undergoing delayed or immediate autologous breast reconstruction in the setting of post-mastectomy radiation therapy.

Methods-Patients enrolled in the Mastectomy Reconstruction Outcomes Consortium Study, who received post-mastectomy radiotherapy and had immediate or delayed free abdominal-based autologous breast reconstruction were identified. Postoperative complications at one and two years after reconstruction were assessed. Patient reported outcomes were evaluated using the BREASTQ questionnaire preoperatively, at one and two-years postoperatively. Bivariate analyses and mixed-effects regression models were used to compare outcomes.
\end{abstract}

Results-A total of 175 patients met our inclusion criteria. Immediate reconstructions were performed in 108 patients and delayed reconstructions in 67 patients. 93.5\% of the immediate reconstructions were performed at a single center. Overall complication rates were similar based on reconstructive timing ( $25.9 \%$ immediate and $26.9 \%$ delayed at one year; $\mathrm{p}=0.54)$. Patients with delayed reconstruction reported significantly lower pre-reconstruction scores $(\mathrm{p}<0.0001)$ for satisfaction with breast, psychosocial and sexual well-being than did patients with immediate reconstruction. At one and two years postoperatively, both groups of patients reported comparable levels of satisfaction in assessed BREAST-Q domains.

\footnotetext{
Corresponding Author: Adeyiza O. Momoh, MD, Section of Plastic Surgery, University of Michigan Health System, 2130 Taubman Center, SPC 5340, 1500 E. Medical Center Drive, Ann Arbor, MI 48109-5340, amomoh@ med.umich.edu, Phone: 734-936-8925, Fax: 734-763-5354.

To be presented at Plastic Surgery The Meeting, September 2016, in Los Angeles, CA.
} 
Conclusions-From this prospective cohort, immediate autologous breast reconstruction in the setting of post-mastectomy radiation therapy appears to be a safe option that may be considered in select patients and centers. Breast aesthetics and quality of life, evaluated from the patient's perspective, were not compromised by flap exposure to radiation therapy.

\section{Keywords}

Autologous breast reconstruction; flaps; post-mastectomy radiotherapy; complications; morbidity; patient reported outcome; BREAST-Q; MROC

\section{Introduction}

Radiotherapy has widespread use in breast cancer. Indications for radiation, especially in the adjuvant setting, have broadened. In conjunction with surgery, radiation is a foundational component of multimodal treatment for locally advanced breast cancer. Post-mastectomy radiation therapy (PMRT) has been shown to increase overall survival and decrease locoregional recurrence in patients with node positive disease ${ }^{1-4}$. However, PMRT can negatively affect breast reconstruction, thus complicating the timing and method of reconstruction used.

Multiple studies have reported on the increased morbidity associated with all forms of immediate breast reconstruction in the setting of $\mathrm{PMRT}^{5-7}$. Early studies on flap exposure to radiation found significant rates of flap fibrosis, fat necrosis, and shrinkage which in severe cases could necessitate flap replacement ${ }^{8,9}$. Consequently, patients undergoing PMRT have been traditionally offered delayed autologous breast reconstruction in efforts to minimize post-operative complications and compromise of the quality of the transferred soft tissue. Delayed autologous breast reconstruction avoids exposure of flap tissue to radiation and offers the restoration of a breast mound that closely approximates natural breast tissue. These benefits come at a price to the patient who lives without a breast for a substantial period of time ${ }^{10-16}$. Immediate breast reconstruction, on the other hand, optimizes breast aesthetics by limiting scars and potentially avoids the psychosocial sequelae of a mastectomy alone ${ }^{17}$.

In recent years, a few studies have reported on favorable outcomes with immediate breast reconstruction with subsequent PMRT ${ }^{18-21}$. Chatterjee et al. demonstrated no significant reduction in flap volumes in patients who underwent PMRT as compared to women who did not have radiation therapy ${ }^{19}$. Others reported acceptable aesthetic outcomes in the setting of flap radiation with limited revision procedures required ${ }^{20,21}$. Most studies to date have however been retrospective evaluations of single center experiences, with limited information on outcomes from the patient's perspective. The purpose of this study is to prospectively evaluate postoperative morbidity and breast specific patient reported outcomes in women who have undergone immediate and delayed autologous breast reconstruction in the setting of PMRT. 


\section{Methods}

\section{Study Population}

Patients were recruited as part of the Mastectomy Reconstruction Outcomes Consortium (MROC) Study, a five-year prospective, multicenter cohort study of mastectomy reconstruction patients funded by the National Cancer Institute (NCI 1RO1CA152192). Fifty-seven plastic surgeons from 11 centers in the USA (Michigan, New York, Illinois, Ohio, Massachusetts, Washington, D.C., Georgia and Texas) and Canada (British Columbia and Manitoba) contributed patients to the study, which began in February 2012. Appropriate Institutional Review Board (IRB) approval was obtained from all sites.

Women, 18 years or older, undergoing first-time, unilateral or bilateral mastectomy with immediate or delayed breast reconstruction, were eligible for MROC study. For the purposes of this study, 175 patients met our inclusion criteria, having undergone PMRT and either immediate or delayed abdominally-based autologous breast reconstruction. Our cohort also had to have at least one year of post-reconstruction follow-up. Eligible reconstruction methods were: free transverse rectus abdominis musculocutaneous (FTRAM) flaps; deep inferior epigastric perforator (DIEP) flaps; superficial inferior epigastric perforator (SIEA) flaps; or a mixture of two of these procedures in bilateral cases. Patients who underwent radiation prior to mastectomy, patients with both immediate and delayed reconstructions or with tissue expanders or implants at the time of reconstruction were excluded. Reconstructive procedure choice was based on patient and surgeon preference.

\section{Statistical Analyses}

Clinical and demographic characteristics between immediate and delayed patients were compared using chi-square tests. For clinical outcomes, breast and donor site complications at one year were summarized as counts and percentages for each group. A mixed-effects logistic regression model was further performed with dependent variable being the presence/ absence of any type of breast complication. The model included radiation timing (immediate vs. delayed) as the primary predictor. The model also included clinical and demographic characteristics as covariates, and random intercepts for centers (hospitals) to account for between-center variability. Adjusted odds ratios (ORs) with 95\% confidence intervals (CIs) as well as corresponding p-values from the model were reported.

For patient-reported outcomes (PRO), we focused on five domains of BREAST-Q measures: satisfaction with breast, psychosocial well-being, physical well-being (chest and upper body), physical well-being (abdomen), and sexual well-being. Mean PRO scores before surgery and the mean difference of PRO from pre- to post-surgery were summarized separately for the two groups (immediate vs. delayed breast reconstruction). To further compare one year and two year PRO between the groups, separate mixed-effects regression models were employed for each PRO measure. Each model was adjusted for baseline value of the corresponding outcome variable and adjusted for clinical and demographic characteristics. The model also included centers (hospitals) as random intercepts to account for between-center variability. To reduce potential bias from non-response or missing PRO at one and two years, analyses were weighted by the inverse-of-the-probability-of-response. 
The probability-of-response was estimated based on data from all eligible study participants $(\mathrm{N}=175)$, where a separate logistic regression model was fit for each outcome measure, with non-missing response status as the dependent variable and baseline patient characteristics and baseline values of the outcome variable as predictors. All statistical analyses were performed in SAS 9.4 (SAS Institute, Cary, NC).

\section{Results}

In 175 patients who met our inclusion criteria, immediate autologous breast reconstructions with PMRT were performed in 108 patients and delayed breast reconstructions after PMRT were performed in 67 patients. Table 1 outlines pertinent demographic and oncologic characteristics of the cohort. Both groups of patients had similar demographic distributions and treatment variables with the exception of the laterality of reconstruction, specific reconstruction types, ethnicity, and the timing of the delivery of chemotherapy. Bilateral reconstructions were performed more often in the immediate setting (34.3\% vs $13.4 \%)$. More DIEP and SIEA flaps were performed in the immediate reconstruction group and free TRAM flaps were performed more frequently in the delayed reconstruction group. As would be expected chemotherapy was delivered after reconstruction with greater frequency in patients undergoing immediate breast reconstruction ( $75 \%$ vs. $3 \%)$. Most of the immediate reconstructions $(n=101,93.5 \%)$ included in the study were performed at a single center, with the rest performed at 4 other centers. Delayed reconstructions were more evenly distributed among 8 centers. The average time from completion of radiation therapy to reconstruction was 24.7 months (range 2.9 to 163.8 months).

Breast and abdominal donor site complications are presented in Table 2. Postoperative breast complications occurred in $26.3 \%$ of the patients, with mastectomy flap necrosis representing the complication with the highest rate of occurrence (7.4\%). Overall complication rates for the immediate and delayed reconstruction groups were similar (25.9\% and 26.9\% respectively; $\mathrm{p}=0.540$ ). With the exception of higher partial flap necrosis in patients undergoing delayed reconstruction $(7.5 \%$ vs $0 \%, \mathrm{p}=0.008)$, specific flap complications including flap loss, fat necrosis, dehiscence, hematomas and seromas were not higher with immediate reconstruction. Mastectomy flap necrosis occurred exclusively in the immediate reconstruction group (12.0\%) as expected. Abdominal donor site complications were also similar for both groups of patients with the exception of a higher seroma rate in the immediate reconstruction patients $(13.0 \%$ vs. $1.5 \%, \mathrm{p}=0.01)$. Even after controlling for demographic and clinical covariates, no significant difference was found for overall breast complications in patients with immediate or delayed breast reconstruction at one and two years after reconstruction (Table 3 ). Patients with a BMI $>30$ had greater odds of overall breast complications (OR 2.54, 95\% CI 1.14-5.68, $\mathrm{p}=0.023$ ) compared to patients with a $\mathrm{BMI}<30$, one year after reconstruction.

Prior to reconstruction, patients undergoing delayed autologous breast reconstruction reported significantly lower scores for the BREAST-Q domains of satisfaction with breast (36.3 vs. 59.5, $\mathrm{p}<0.0001$ ), psychosocial well-being (50 vs. 66.1, $\mathrm{p}<0.0001$ ) and sexual wellbeing ( 29.8 vs. $52.1, \mathrm{p}<0.0001)$ (Table 4). Controlling for baseline measures and covariates, at one and two years after reconstruction, patients reported no difference in scores in all but 
one of the assessed BREAST-Q domains between the delayed and immediate reconstruction groups; at two years of follow-up physical well-being of the chest was scored higher (80.6 vs $70.5, \mathrm{p}=0.048$ ) in patients with delayed reconstruction. Patients in both groups reported significantly higher breast satisfaction at one and two years post-surgery compared to baseline $(\mathrm{p}=0.018$ for immediate at one year and $\mathrm{p}=0.047$ at two years, and $\mathrm{p}<0.0001$ for delayed at both time intervals, Table 5). Delayed reconstruction patients also had improved psychosocial well-being ( $p<0.0001$ at one and two years) and sexual well-being $(\mathrm{p}<0.0001$ at one and two years) compared to baseline. Physical well-being for abdomen was not fully restored for both groups at one year (within-patient mean difference $=-10.9, \mathrm{p}<0.0001$ for immediate, $=-9.2, \mathrm{p}=0.001$ for delayed), although it was nearly restored for delayed group by year 2 ( -10.1 for immediate, -2.0 for delayed). Similarly, although not statistically significant, physical well-being chest was not fully restored for patients undergoing immediate reconstruction ( -3.0 at one year and -2.4 at two years).

\section{Discussion}

In this study, assessing the effects of PMRT on flap complication rates and patient satisfaction, we have found limited postoperative differences when comparing delayed and immediate autologous breast reconstruction. Overall breast complications for delayed and immediate breast reconstruction were similar at $26.9 \%$ and $25.9 \%$ respectively $(\mathrm{p}=0.540)$. These complication rates fall within the range reported in the literature (6-62.6\%) on DIEP flap breast reconstruction. ${ }^{22-24}$ Also consistent with the reported literature on autologous flap outcomes, patients with higher BMIs ( 30 ), had significantly greater odds for breast complications (OR=2.54, 95\% CI:1.14-5.68) than patients with lower BMIs $(<30) .{ }^{25-27}$ In regard to outcomes, patients undergoing delayed breast reconstruction reported significantly lower scores for baseline satisfaction with breast, psychosocial and sexual well-being relative to similar patients undergoing immediate reconstruction (Table 3). These preoperative PRO differences in patients with delayed versus immediate breast reconstruction had dissipated at one and two years after reconstruction.

Radiotherapy has multiple harmful effects on soft tissue and breast reconstruction ranging from wound healing challenges to skin and flap fibrosis. $8,9,28-38$ With well documented concerns, the general consensus has been to approach immediate reconstruction in patients requiring PMRT with caution and delay flap reconstruction until after radiation therapy in order to optimize reconstructive results and decrease radiation-associated flap complications. ${ }^{39}$ Over time, there has been a swell in the level of interest for immediate breast reconstruction. National rates for immediate reconstruction have risen annually, and the need for radiation does not appear to have deterred this growth. ${ }^{40,41}$ With this in mind, a few authors have further explored the feasibility of immediate autologous breast reconstruction with PMRT. ${ }^{20,21,42,43}$ Mirzabeigi et al. retrospectively evaluated 407 patients undergoing immediate free flap reconstructions at a single institution. ${ }^{21}$ Of these patients, 127 were exposed to PMRT and compared to 280 non-radiated patients. They found a higher incidence of volume loss and fat necrosis in both unilateral and bilateral flap reconstructions exposed to radiation; however, revision procedures in radiated and non-radiated flaps were similar. ${ }^{21}$ Studies by Chang et al. and Taghizadeh et al. found no differences in complications between radiated and non-radiated free flap breast reconstruction. 
Complications they assessed included fat necrosis, wound healing, and additional surgical procedures for associated volume deficiencies. ${ }^{20,43}$

The reality is that radiation protocols even at centers of excellence within the United States differ, and therefore the results of our current study must be interpreted with this in mind. Consistent with recent research, this current study's findings suggest that immediate abdominal-based breast reconstruction in women undergoing PMRT can be safe and without significant morbidity. Complication rates between the delayed and immediate reconstruction groups were similar. There were no differences in major or minor complications including delayed wound healing, infection, flap loss, or fat necrosis between our two cohorts at one year. Overall complications were also not affected at two years of follow up. Though we did not evaluate volume changes and degree of firmness or fibrosis as part of the study, these concerns are assessed indirectly from the patient's perspective, which is arguably the most important end point in this context.

Understanding that immediate breast reconstruction offers important psychosocial and physical benefits to women undergoing mastectomy, we sought to evaluate satisfaction and quality of life changes related to immediate and delayed flap reconstruction with PMRT. ${ }^{44}$ With the use of BREAST-Q, we found that patients undergoing delayed autologous breast reconstruction reported lower preoperative scores for breast satisfaction and psychosocial and sexual well-being (Table 4), thus corroborating previous findings on timing of reconstruction. ${ }^{17}$ However, at one year and two years post-reconstruction, these differences did not exist between the immediate and delayed breast reconstruction groups. Physical well-being of the chest in patients with immediate reconstruction was however lower than in those with delayed reconstruction at the end of the observation period. Postoperative breast satisfaction, which assesses the patient's perspective on issues such as aesthetics, softness, and symmetry were similar for both groups of patients. Additionally, quality of life from the psychosocial and sexual standpoint was equivalent in both groups of patients. Previous attempts at evaluating aesthetic outcomes on immediate flap reconstruction with PMRT have done so primarily from the surgeon's perspective. $9,31,32,42,45$ Though the surgeon's assessment of aesthetic outcomes is of value, an evaluation of aesthetic outcomes in addition to quality of life measures from the patient's perspective is even more vital. Our findings indicate that women in this cohort who underwent immediate autologous breast reconstruction have high levels of satisfaction preoperatively and continue to be content with their reconstructed breasts after radiation.

Our findings may relate in part to advances in radiation techniques, including threedimensional planning and simple intensity modulation, which increasingly allow for greater dose homogeneity within the treated fields. Of note, the vast majority of our patients with immediate flap reconstruction were managed at a single academic center within the MROC consortium. The radiation protocol at that center therefore merits specific consideration: a total dose was typically $50.4 \mathrm{~Gy}$ in 28 fractions of 1.8 Gy per day, with the use of field-infield, intensity-modulated radiation therapy (IMRT) to deliver treatment to the reconstructed breast. A boost to the reconstructed breast was not utilized. Moreover, 45 Gy in 25 fractions was delivered to nodes as believed to be indicated by the local radiation oncologists; for instance, internal mammary nodes were treated in patients with medial tumors or other high 
risk features such as $\mathrm{N} 2$ disease. This regimen is not atypical in the context of international practice patterns in this setting ${ }^{46}$, although many institutions, including the senior author's center, utilize slightly larger (2 Gy) fractions, which may increase late effects. Also of potential relevance is the fact that bolus may be utilized at other centers to increase the dose to the skin as an intentional target of treatment, again with possible implications for acute and late toxicity. Such subtle differences in radiation techniques may be meaningful, and those seeking to generalize from this study's results should consider whether the radiation protocols at their own institution vary considerably from those used for the vast majority of patients with immediate reconstructions considered in this study. Also with potential implications for many institutions are findings from recent radiation oncology studies that show benefits of decreased recurrence ${ }^{47}$ and improved survival ${ }^{48}$ with regional nodal radiation in patients with node-positive early stage breast cancer; although some of the patients treated with radiation in this series did receive treatment to the internal mammary nodes, radiation oncologists may now choose to treat this region in a larger proportion of patients receiving post-mastectomy radiotherapy, with possible implications for both toxicity and radiotherapeutic coverage.

The overwhelming evidence in the literature indicates that immediate breast reconstruction is oncologically safe. ${ }^{49-51}$ A topic of considerable debate however relates to the potential for compromised delivery of radiation to the chest wall with a reconstructed breast in place..$^{52}$ Motwani and colleagues, evaluating their institutional experience with delivery of radiation to primarily autologous flaps observed some degree of compromise in the delivery of radiation to $52 \%$ of reconstructed patients compared to $7 \%$ in matched controls without reconstruction, when delivery of 45-50 Gy to the internal mammary region was one of the criteria by which adequacy was judged. ${ }^{52}$ These findings are in contrast to a number of studies from other institutions that have shown no compromise to the delivery of radiation therapy to the chest wall with immediate breast reconstruction. ${ }^{53-55}$ Using standard field arrangements and 3D planning, Chung et al., demonstrated that they were able to achieve excellent coverage of the reconstructed breast and IMNs in patients with implant and autologous breast reconstruction, although it is important to note that mean heart dose was non-trivial (5.8 Gy) in left-sided patients in whom internal mammary treatment was delivered ${ }^{53}$ Given growing recognition of the importance of minimizing cardiac dose, consideration of advanced radiation techniques such as breathing control is important for all patients with left-sided disease, and particularly those receiving internal mammary treatment, whether the patient has received reconstruction or not.

This study has a number of strengths, which include the prospective multi-center design. The prospective nature of this project allows for rigorous and standardized measurement of preoperative confounders, for which the analyses may then appropriately control, and the documentation of PRO changes that occur over time. The planned multi-center design was limited by the fact that most of the immediate reconstructions were performed at one center, limiting the generalizability of our findings. Other limitations include a relatively small sample size and the length of follow-up; the length of follow-up bares importance given the potential for late effects of radiation. However, we followed patients for two years postreconstruction, similar to other studies on long-term patient reported outcomes on reconstruction. ${ }^{44}$ Longer term studies on this topic would be of great value. 


\section{Conclusion}

From this prospective cohort, immediate autologous breast reconstruction in the setting of PMRT appears to be a safe option that may be considered in select patients and centers. Breast aesthetics and quality of life, evaluated prospectively from the patient's perspective, were not compromised by flap exposure to radiotherapy. Given the known benefits of immediate breast reconstruction to the patient, immediate autologous breast reconstruction should at least be considered even in patients who will require radiotherapy. Though not generalizable to all centers, these findings emphasize the importance of intentional multidisciplinary involvement and exchange between specialists involved in the care of this patient population.

\section{Acknowledgments}

Support for this study was provided by a grant from the National Cancer Institute (1R01CA152192) to A.L.P. and E.G.W.

\section{References}

1. Overgaard M, Hansen PS, Overgaard J, et al. Postoperative radiotherapy in high-risk premenopausal women with breast cancer who receive adjuvant chemotherapy. Danish Breast Cancer Cooperative Group 82b Trial. The New England journal of medicine. 1997; 337:949-55. [PubMed: 9395428]

2. Ragaz J, Jackson SM, Le N, et al. Adjuvant radiotherapy and chemotherapy in node-positive premenopausal women with breast cancer. The New England journal of medicine. 1997; 337:95662. [PubMed: 9309100]

3. McGale P, Taylor C, Correa C, et al. Effect of radiotherapy after mastectomy and axillary surgery on 10-year recurrence and 20-year breast cancer mortality: meta-analysis of individual patient data for 8135 women in 22 randomised trials. Lancet. 2014; 383:2127-35. [PubMed: 24656685]

4. Carlson RW, Allred DC, Anderson BO, et al. Breast cancer. Clinical practice guidelines in oncology. Journal of the National Comprehensive Cancer Network: JNCCN. 2009; 7:122-92. [PubMed: 19200416]

5. Barry M, Kell MR. Radiotherapy and breast reconstruction: a meta-analysis. Breast cancer research and treatment. 2011; 127:15-22. [PubMed: 21336948]

6. Berry T, Brooks S, Sydow N, et al. Complication rates of radiation on tissue expander and autologous tissue breast reconstruction. Annals of surgical oncology. 2010; 17(Suppl 3):202-10. [PubMed: 20853034]

7. El-Sabawi B, Sosin M, Carey JN, Nahabedian MY, Patel KM. Breast reconstruction and adjuvant therapy: A systematic review of surgical outcomes. Journal of surgical oncology. 2015; 112:458-64. [PubMed: 26345465]

8. Tran NV, Evans GR, Kroll SS, et al. Postoperative adjuvant irradiation: effects on tranverse rectus abdominis muscle flap breast reconstruction. Plastic and reconstructive surgery. 2000; 106:313-7. discussion 8-20. [PubMed: 10946929]

9. Rogers NE, Allen RJ. Radiation effects on breast reconstruction with the deep inferior epigastric perforator flap. Plastic and reconstructive surgery. 2002; 109:1919-24. discussion 25-6. [PubMed: 11994594]

10. Goin MK, Goin JM. Psychological reactions to prophylactic mastectomy synchronous with contralateral breast reconstruction. Plastic and reconstructive surgery. 1982; 70:355-9. [PubMed: 7111487]

11. Steinberg MD, Juliano MA, Wise L. Psychological outcome of lumpectomy versus mastectomy in the treatment of breast cancer. The American journal of psychiatry. 1985; 142:34-9. [PubMed: 3966584] 
12. Mendelson BC. The psychological basis for breast reconstruction following mastectomy. The Medical journal of Australia. 1980; 1:517-8. [PubMed: 7393027]

13. Sneeuw KC, Aaronson NK, Yarnold JR, et al. Cosmetic and functional outcomes of breast conserving treatment for early stage breast cancer. 1. Comparison of patients' ratings, observers' ratings, and objective assessments. Radiotherapy and oncology: journal of the European Society for Therapeutic Radiology and Oncology. 1992; 25:153-9. [PubMed: 1470691]

14. Abt V, McGurrin MC, Heintz L. The impact of mastectomy on sexual self-image, attitudes, and behavior. Journal of Sex Education and Therapy. 1978; 4

15. Schain, WS. Sexual Problems of Patients with Cancer. In: deVita, VT.Hellman, TS., Rosenberg, SA., editors. Cancer: Principles and Practices in Oncology. Philadelphia: Lippincott; 1992.

16. Silberfarb PM, Maurer LH, Crouthamel CS. Psychosocial aspects of neoplastic disease: I. Functional status of breast cancer patients during different treatment regimens. The American journal of psychiatry. 1980; 137:450-5. [PubMed: 7361931]

17. Wilkins EG, Cederna PS, Lowery JC, et al. Prospective analysis of psychosocial outcomes in breast reconstruction: one-year postoperative results from the Michigan Breast Reconstruction Outcome Study. Plastic and reconstructive surgery. 2000; 106:1014-25. discussion 26-7. [PubMed: 11039373]

18. Albino FP, Koltz PF, Ling MN, Langstein HN. Irradiated autologous breast reconstructions: effects of patient factors and treatment variables. Plastic and reconstructive surgery. 2010; 126:12-6. [PubMed: 20220558]

19. Chatterjee JS, Lee A, Anderson W, et al. Effect of postoperative radiotherapy on autologous deep inferior epigastric perforator flap volume after immediate breast reconstruction. The British journal of surgery. 2009; 96:1135-40. [PubMed: 19787763]

20. Chang EI, Liu TS, Festekjian JH, Da Lio AL, Crisera CA. Effects of radiation therapy for breast cancer based on type of free flap reconstruction. Plastic and reconstructive surgery. 2013; 131:1e8e. [PubMed: 22965239]

21. Mirzabeigi MN, Smartt JM, Nelson JA, Fosnot J, Serletti JM, Wu LC. An assessment of the risks and benefits of immediate autologous breast reconstruction in patients undergoing postmastectomy radiation therapy. Annals of plastic surgery. 2013; 71:149-55. [PubMed: 23542828]

22. Nahabedian MY, Momen B, Galdino G, Manson PN. Breast Reconstruction with the free TRAM or DIEP flap: patient selection, choice of flap, and outcome. Plastic and reconstructive surgery. 2002; 110:466-75. discussion 76-7. [PubMed: 12142662]

23. Hamdi M, Weiler-Mithoff EM, Webster MH. Deep inferior epigastric perforator flap in breast reconstruction: experience with the first 50 flaps. Plastic and reconstructive surgery. 1999; 103:8695. [PubMed: 9915167]

24. Blondeel PN. One hundred free DIEP flap breast reconstructions: a personal experience. British journal of plastic surgery. 1999; 52:104-11. [PubMed: 10434888]

25. Hanwright PJ, Davila AA, Hirsch EM, et al. The differential effect of BMI on prosthetic versus autogenous breast reconstruction: a multivariate analysis of 12,986 patients. Breast. 2013; 22:93845. [PubMed: 23769660]

26. Ozturk CN, Kundu N, Bernard S, Cooper K, Ozturk C, Djohan R. Breast reconstruction with abdominal-based free flaps in high body mass index population: postoperative complications and impact of weight loss. Annals of plastic surgery. 2014; 72:13-22. [PubMed: 23542834]

27. Schaverien MV, McCulley SJ. Effect of obesity on outcomes of free autologous breast reconstruction: a meta-analysis. Microsurgery. 2014; 34:484-97. [PubMed: 24652691]

28. Ascherman JA, Hanasono MM, Newman MI, Hughes DB. Implant reconstruction in breast cancer patients treated with radiation therapy. Plastic and reconstructive surgery. 2006; 117:359-65. [PubMed: 16462313]

29. Spear SL, Ducic I, Low M, Cuoco F. The effect of radiation on pedicled TRAM flap breast reconstruction: outcomes and implications. Plastic and reconstructive surgery. 2005; 115:84-95. [PubMed: 15622237]

30. Spear SL, Onyewu C. Staged breast reconstruction with saline-filled implants in the irradiated breast: recent trends and therapeutic implications. Plastic and reconstructive surgery. 2000; 105:930-42. [PubMed: 10724252] 
31. Tran NV, Chang DW, Gupta A, Kroll SS, Robb GL. Comparison of immediate and delayed free TRAM flap breast reconstruction in patients receiving postmastectomy radiation therapy. Plastic and reconstructive surgery. 2001; 108:78-82. [PubMed: 11420508]

32. Williams JK, Carlson GW, Bostwick J, Bried JT, Mackay G. The effects of radiation treatment after TRAM flap breast reconstruction. Plastic and reconstructive surgery. 1997; 100:1153-60. [PubMed: 9326776]

33. Tibbs MK. Wound healing following radiation therapy: a review. Radiotherapy and oncology: journal of the European Society for Therapeutic Radiology and Oncology. 1997; 42:99-106. [PubMed: 9106919]

34. Thanik VD, Chang CC, Zoumalan RA, et al. A novel mouse model of cutaneous radiation injury. Plastic and reconstructive surgery. 2011; 127:560-8. [PubMed: 21285760]

35. Archambeau JO, Pezner R, Wasserman T. Pathophysiology of irradiated skin and breast. International journal of radiation oncology, biology, physics. 1995; 31:1171-85.

36. O'Sullivan B, Levin W. Late radiation-related fibrosis: pathogenesis, manifestations, and current management. Seminars in radiation oncology. 2003; 13:274-89. [PubMed: 12903016]

37. Fosnot J, Fischer JP, Smartt JM Jr, et al. Does previous chest wall irradiation increase vascular complications in free autologous breast reconstruction? Plastic and reconstructive surgery. 2011; 127:496-504. [PubMed: 20966818]

38. Fracol ME, Basta MN, Nelson JA, et al. Bilateral Free Flap Breast Reconstruction After Unilateral Radiation: Comparing Intraoperative Vascular Complications and Postoperative Outcomes in Radiated Versus Nonradiated Breasts. Annals of plastic surgery. 2016; 76:311-4. [PubMed: 26545214]

39. Kronowitz SJ, Robb GL. Radiation therapy and breast reconstruction: a critical review of the literature. Plastic and reconstructive surgery. 2009; 124:395-408. [PubMed: 19644254]

40. Agarwal S, Kidwell KM, Farberg A, Kozlow JH, Chung KC, Momoh AO. Immediate Reconstruction of the Radiated Breast: Recent Trends Contrary to Traditional Standards. Annals of surgical oncology. 2015; 22:2551-9. [PubMed: 25564172]

41. Jagsi R, Jiang J, Momoh AO, et al. Trends and variation in use of breast reconstruction in patients with breast cancer undergoing mastectomy in the United States. Journal of clinical oncology: official journal of the American Society of Clinical Oncology. 2014; 32:919-26. [PubMed: 24550418]

42. Clarke-Pearson EM, Chadha M, Dayan E, et al. Comparison of irradiated versus nonirradiated DIEP flaps in patients undergoing immediate bilateral DIEP reconstruction with unilateral postmastectomy radiation therapy (PMRT). Annals of plastic surgery. 2013; 71:250-4. [PubMed: 23945528]

43. Taghizadeh R, Moustaki M, Harris S, Roblin P, Farhadi J. Does post-mastectomy radiotherapy affect the outcome and prevalence of complications in immediate DIEP breast reconstruction? A prospective cohort study. Journal of plastic, reconstructive \& aesthetic surgery: JPRAS. 2015; 68:1379-85. [PubMed: 26210234]

44. Atisha D, Alderman AK, Lowery JC, Kuhn LE, Davis J, Wilkins EG. Prospective analysis of longterm psychosocial outcomes in breast reconstruction: two-year postoperative results from the Michigan Breast Reconstruction Outcomes Study. Annals of surgery. 2008; 247:1019-28. [PubMed: 18520230]

45. Spear SL, Newman MK, Bedford MS, Schwartz KA, Cohen M, Schwartz JS. A retrospective analysis of outcomes using three common methods for immediate breast reconstruction. Plastic and reconstructive surgery. 2008; 122:340-7. [PubMed: 18626348]

46. Taghian A, Jagsi R, Makris A, et al. Results of a survey regarding irradiation of internal mammary chain in patients with breast cancer: practice is culture driven rather than evidence based. International journal of radiation oncology, biology, physics. 2004; 60:706-14.

47. Whelan TJ, Olivotto IA, Parulekar WR, et al. Regional nodal irradiation in early-stage breast cancer. NEJM. 2015; 373:307-16. [PubMed: 26200977]

48. Thorsen LB, Offersen BV, Dano H, et al. DBCG-IMN: A population-based cohort study on the effect of internal mammary node irradiation in early node-positive breast cancer. J Clin Oncol. 2016; 34(4):314-20. [PubMed: 26598752] 
49. Langstein HN, Cheng MH, Singletary SE, et al. Breast cancer recurrence after immediate reconstruction: patterns and significance. Plast Reconstr Surg. 2003; 111:712-720. [PubMed: 12560692]

50. Howard MA, Polo K, Pusic AL, et al. Breast cancer local recurrence after mastectomy and TRAM flap reconstruction: incidence and treatment options. Plast Reconstr Surg. 2006; 117:1381-1386. [PubMed: 16641702]

51. Huang CJ, Hou MF, Lin SD. Comparison of local recurrence and distant metastases between breast cancer patients after postmastectomy radiotherapy with and without immediate TRAM flap reconstruction. Plast Reconstr Surg. 2006; 118:1079-86. [PubMed: 17016170]

52. Motwani SB, Strom EA, Schechter NR, et al. The impact of immediate breast reconstruction on the technical delivery of postmastectomy radiotherapy. Int J Radiat Oncol Biol Phys. 2006; 66:76-82. [PubMed: 16765534]

53. Chung E, Marsh RB, Griffith KA, Moran JM, Pierce LJ. Quantifying dose to the reconstructed breast: Can we adequately treat? Med Dosim. 2013; 38:55-59. [PubMed: 22901747]

54. Ohri N, Cordeiro PG, Keam J, et al. Quantifying the impact of immediate reconstruction in postmastectomy radiation: A large, dose-volume histogram-based analsyis. Int J Radiat Oncol Biol Phys. 2012; 84:e153-9. [PubMed: 22560544]

55. Ho AY, Patel N, Ohri N, et al. Bilateral implant reconstruction does not affect the quality of postmastectomy radiation therapy. Med Dosim. 2014; 39:18-22. [PubMed: 24238837] 
Table 1

Clinical and Socio-demographic Characteristics of the Study Sample

\begin{tabular}{|c|c|c|c|c|}
\hline \multirow{3}{*}{ Variable } & \multirow{3}{*}{$\begin{array}{c}\text { Overall } \\
\mathrm{N}=175\end{array}$} & \multicolumn{2}{|c|}{ Timing } & \multirow{3}{*}{ p-Value } \\
\hline & & \multirow{2}{*}{$\begin{array}{c}\text { Immediate } \\
\mathrm{N}=108,61.7 \%\end{array}$} & \multirow{2}{*}{$\begin{array}{c}\text { Delayed } \\
\mathrm{N}=67,38.3 \%\end{array}$} & \\
\hline & & & & \\
\hline \multicolumn{5}{|l|}{ Age } \\
\hline $30-39$ & $19(10.9 \%)$ & $11(10.2 \%)$ & $8(11.9 \%)$ & 0.952 \\
\hline $40-49$ & $52(29.7 \%)$ & $33(30.6 \%)$ & $19(28.4 \%)$ & \\
\hline $50-59$ & $70(40 \%)$ & $44(40.7 \%)$ & $26(38.8 \%)$ & \\
\hline$\checkmark 60$ & $34(19.4 \%)$ & $20(18.5 \%)$ & $14(20.9 \%)$ & \\
\hline \multicolumn{5}{|l|}{ BMI } \\
\hline$<30$ & $91(52 \%)$ & $59(54.6 \%)$ & $32(47.8 \%)$ & 0.377 \\
\hline$>=30$ & $84(48 \%)$ & $49(45.4 \%)$ & $35(52.2 \%)$ & \\
\hline \multicolumn{5}{|l|}{ Race } \\
\hline White & $156(90.7 \%)$ & $97(90.7 \%)$ & $59(90.8 \%)$ & 0.980 \\
\hline Other & $16(9.3 \%)$ & $10(9.4 \%)$ & $6(9.2 \%)$ & \\
\hline \multicolumn{5}{|l|}{ Ethnicity } \\
\hline Hispanic & $10(5.8 \%)$ & $1(0.9 \%)$ & $9(13.4 \%)$ & 0.001 \\
\hline Non-Hispanic & $164(94.3 \%)$ & $106(99.1 \%)$ & $58(86.6 \%)$ & \\
\hline \multicolumn{5}{|l|}{ Education Level } \\
\hline No college degree & $83(47.7 \%)$ & $51(47.7 \%)$ & $32(47.8 \%)$ & 0.990 \\
\hline College degree & $91(52.3 \%)$ & $56(52.3 \%)$ & $35(52.2 \%)$ & \\
\hline \multicolumn{5}{|l|}{ Employment Status } \\
\hline Full-time ${ }^{1}$ & $96(55.5 \%)$ & $57(53.3 \%)$ & $39(59.1 \%)$ & 0.756 \\
\hline Part-time & $20(11.6 \%)$ & $13(12.2 \%)$ & $7(10.6 \%)$ & \\
\hline Unemployed & $57(33 \%)$ & $37(34.6 \%)$ & $20(30.3 \%)$ & \\
\hline \multicolumn{5}{|l|}{ Income } \\
\hline$<50,000$ & $47(27.7 \%)$ & $26(24.8 \%)$ & $21(32.3 \%)$ & 0.162 \\
\hline $50,000-99,999$ & $65(38.2 \%)$ & $46(43.8 \%)$ & $19(29.2 \%)$ & \\
\hline$\geq 100,000$ & $58(34.1 \%)$ & $33(31.4 \%)$ & $25(38.5 \%)$ & \\
\hline \multicolumn{5}{|l|}{ Marital Status } \\
\hline Married or partnered & $137(78.3 \%)$ & $86(79.6 \%)$ & $51(76.1 \%)$ & 0.584 \\
\hline Not married or partnered & $38(21.7 \%)$ & $22(20.4 \%)$ & $16(23.9 \%)$ & \\
\hline \multicolumn{5}{|l|}{ Laterality } \\
\hline Unilateral & $129(73.7 \%)$ & $71(65.7 \%)$ & $58(86.6 \%)$ & 0.002 \\
\hline Bilateral & $46(26.3 \%)$ & $37(34.3 \%)$ & $9(13.4 \%)$ & \\
\hline \multicolumn{5}{|l|}{ Reconstruction type } \\
\hline FTRAM & $21(12 \%)$ & $1(0.9 \%)$ & $20(29.9 \%)$ & $<.001$ \\
\hline DIEP & $115(65.7 \%)$ & $76(70.4 \%)$ & $39(58.2 \%)$ & \\
\hline
\end{tabular}

Plast Reconstr Surg. Author manuscript; available in PMC 2018 June 01. 


\begin{tabular}{|l|c|c|c|c|}
\hline \multirow{2}{*}{ Variable } & Overall & \multicolumn{2}{|c|}{ Timing } & \multirow{2}{*}{ p-Value } \\
\cline { 2 - 4 } & \multirow{2}{*}{$\mathbf{N = 1 7 5}$} & Immediate & Delayed & \\
\cline { 3 - 4 } & & $\mathbf{N = 1 0 8 , 6 1 . 7 \%}$ & N=67, 38.3\% & \\
\hline SIEA & $29(16.6 \%)$ & $24(22.2 \%)$ & $5(7.5 \%)$ & \\
\hline Mixed $^{2}$ & $10(5.7 \%)$ & $7(6.5 \%)$ & $3(4.5 \%)$ & \\
\hline Smoking & & & & \\
\hline Non smoker & $99(56.6 \%)$ & $58(53.7 \%)$ & $41(61.2 \%)$ & 0.600 \\
\hline Previous smoker & $71(40.6 \%)$ & $47(43.5 \%)$ & $24(35.8 \%)$ & \\
\hline Current smoker & $5(2.9 \%)$ & $3(2.8 \%)$ & $2(3 \%)$ & \\
\hline Chemotherapy & & & & \\
\hline After reconstruction & $83(47.4 \%)$ & $81(75 \%)$ & $2(3 \%)$ & $<.001$ \\
\hline Not after reconstruction & $92(52.6 \%)$ & $27(25 \%)$ & $65(97 \%)$ & \\
\hline
\end{tabular}

${ }^{1}$ Full-time employment includes full-time students.

${ }^{2}$ Mixed reconstruction denotes different flap types for each breast in a bilateral reconstruction procedure. 
Table 2

One Year Postoperative Complications in Patients Undergoing Immediate and Delayed Autologous Breast Reconstruction

\begin{tabular}{|c|c|c|c|c|}
\hline & Total $(\mathrm{N}=175)$ & Immediate $(\mathrm{N}=108)$ & Delayed $(\mathrm{N}=67)$ & p-Value ${ }^{I}$ \\
\hline \multicolumn{5}{|l|}{ Breast Complications } \\
\hline Any breast complication & $46(26.3 \%)$ & $28(25.9 \%)$ & $18(26.9 \%)$ & 0.540 \\
\hline Post-operative bleeding or hematoma & $8(4.6 \%)$ & $6(5.6 \%)$ & $2(3.0 \%)$ & 0.712 \\
\hline Wound dehiscence & $10(5.7 \%)$ & $4(3.7 \%)$ & $6(9.0 \%)$ & 0.185 \\
\hline Wound infection requiring oral antibiotics & $4(2.3 \%)$ & $2(1.9 \%)$ & $2(3.0 \%)$ & 0.638 \\
\hline Wound infection requiring IV antibiotics & $2(1.1 \%)$ & $1(0.9 \%)$ & $1(1.49 \%)$ & 1.000 \\
\hline $\begin{array}{l}\text { Wound infection requiring surgical or percutaneous drainage of } \\
\text { abscess }\end{array}$ & $4(2.3 \%)$ & $3(2.8 \%)$ & $1(1.5 \%)$ & 1.000 \\
\hline Mastectomy skin flap necrosis & $13(7.4 \%)$ & $13(12.0 \%)$ & $0(0.0 \%)$ & 0.002 \\
\hline Acute partial flap necrosis & $5(2.9 \%)$ & $0(0.0 \%)$ & $5(7.5 \%)$ & 0.008 \\
\hline Chronic fat necrosis of the reconstructed flap & $11(6.3 \%)$ & $4(3.7 \%)$ & $7(10.5 \%)$ & 0.107 \\
\hline Seroma & $1(0.6 \%)$ & $0(0.0 \%)$ & $1(1.5 \%)$ & 0.383 \\
\hline Total reconstructive flap loss & 0 & 0 & 0 & - \\
\hline \multicolumn{5}{|l|}{ Donor Site Complications } \\
\hline Any donor site complication & $54(30.9 \%)$ & $43(39.8 \%)$ & $11(16.4 \%)$ & 0.244 \\
\hline Post-operative bleeding or hematoma at donor site & $2(1.1 \%)$ & $2(1.9 \%)$ & $0(0.0 \%)$ & 0.525 \\
\hline Wound dehiscence at donor site & $18(10.3 \%)$ & $13(12.0 \%)$ & $5(7.5 \%)$ & 0.445 \\
\hline Wound infection at donor site requiring oral antibiotics & $4(2.3 \%)$ & $4(3.7 \%)$ & $0(0.0 \%)$ & 0.299 \\
\hline Wound infection at donor site requiring IV antibiotics & $2(1.1 \%)$ & $1(0.9 \%)$ & $1(1.5 \%)$ & 1.000 \\
\hline $\begin{array}{l}\text { Wound infection at the donor site requiring surgical or } \\
\text { percutaneous drainage of abscess }\end{array}$ & $2(1.1 \%)$ & $2(1.9 \%)$ & $0(0.0 \%)$ & 0.525 \\
\hline Donor site necrosis & $9(5.1 \%)$ & $8(7.4 \%)$ & $1(1.5 \%)$ & 0.156 \\
\hline Chronic fat necrosis of the donor site & $5(2.9 \%)$ & $3(2.8 \%)$ & $2(3.0 \%)$ & 1.000 \\
\hline Donor site seroma & $15(8.6 \%)$ & $14(13.0 \%)$ & $1(1.5 \%)$ & 0.010 \\
\hline Abdominal wall bulge, laxity or hernia & $3(1.7 \%)$ & $1(0.9 \%)$ & $2(3.0 \%)$ & 0.559 \\
\hline
\end{tabular}

${ }^{1}$ Based on Fisher's exact test for individual complication items, based on mixed-effects logistic regression model for any breast complication and any donor site complication. 


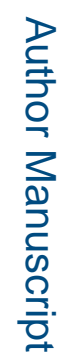

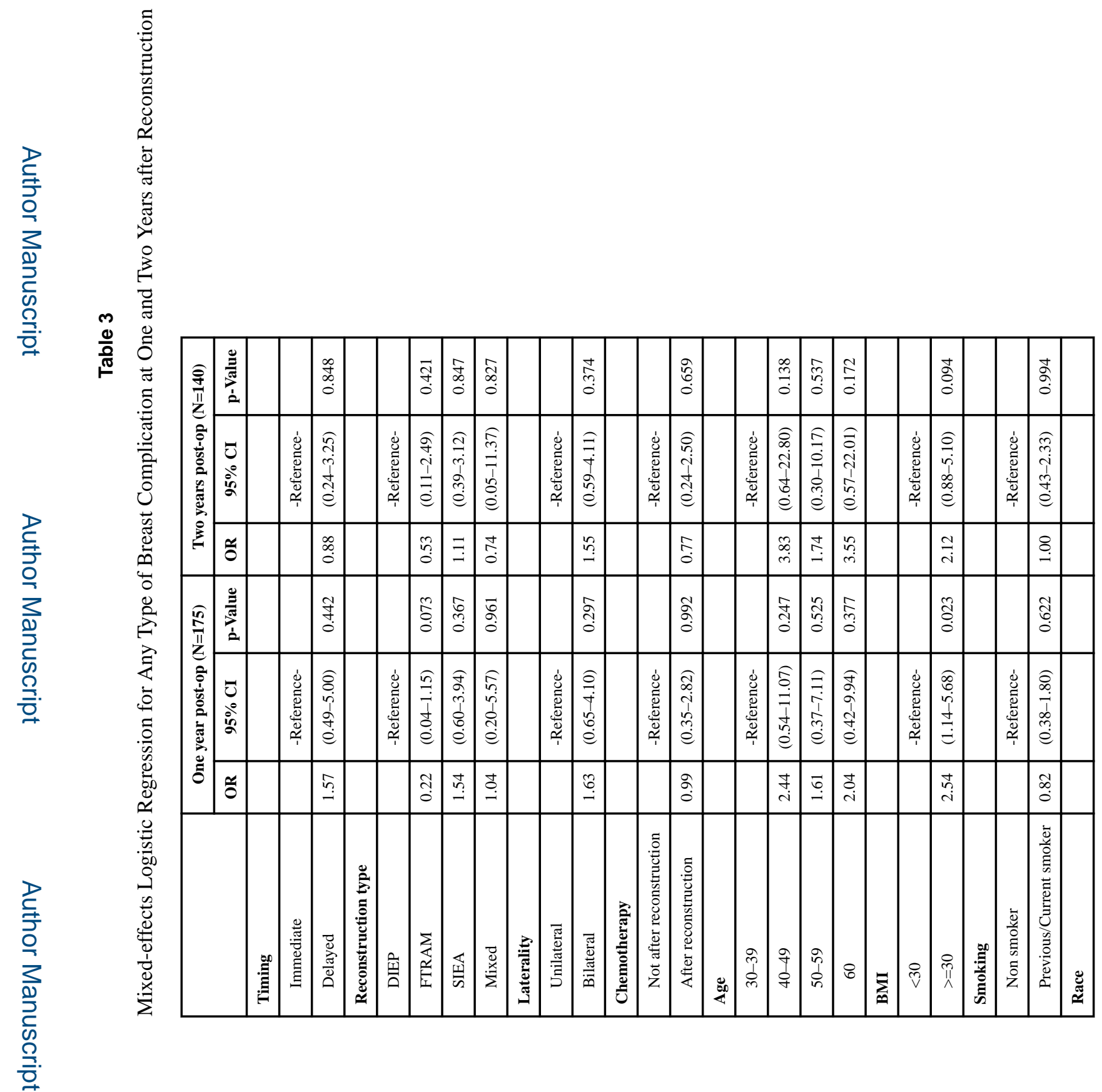

Plast Reconstr Surg. Author manuscript; available in PMC 2018 June 01. 


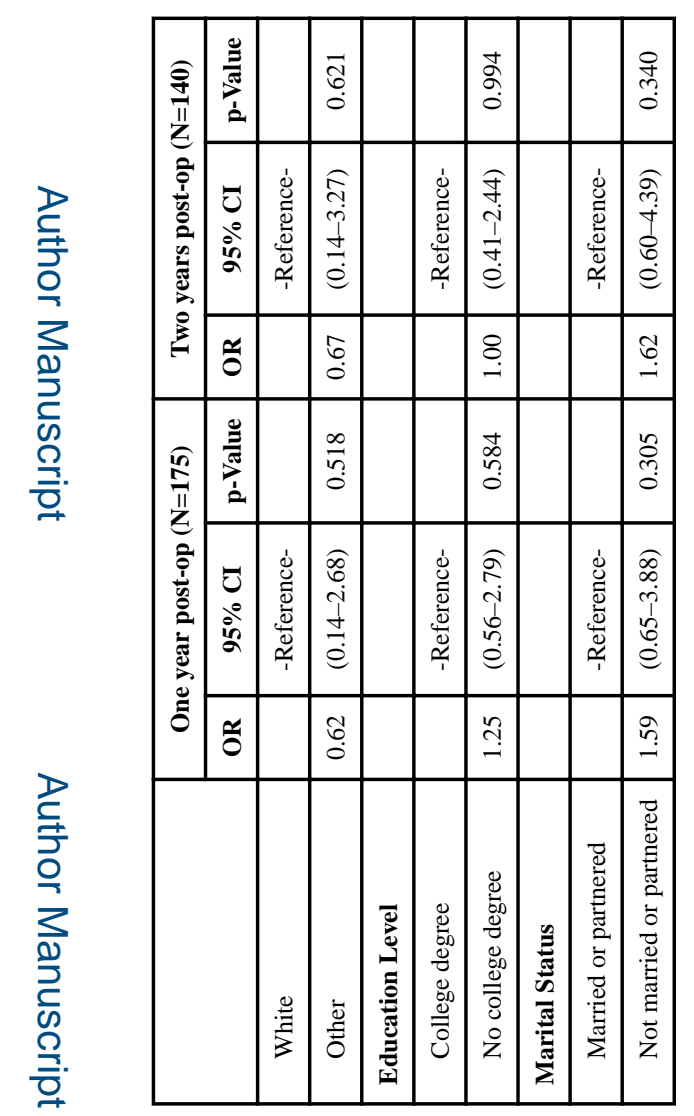

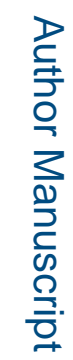

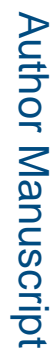

Plast Reconstr Surg. Author manuscript; available in PMC 2018 June 01. 


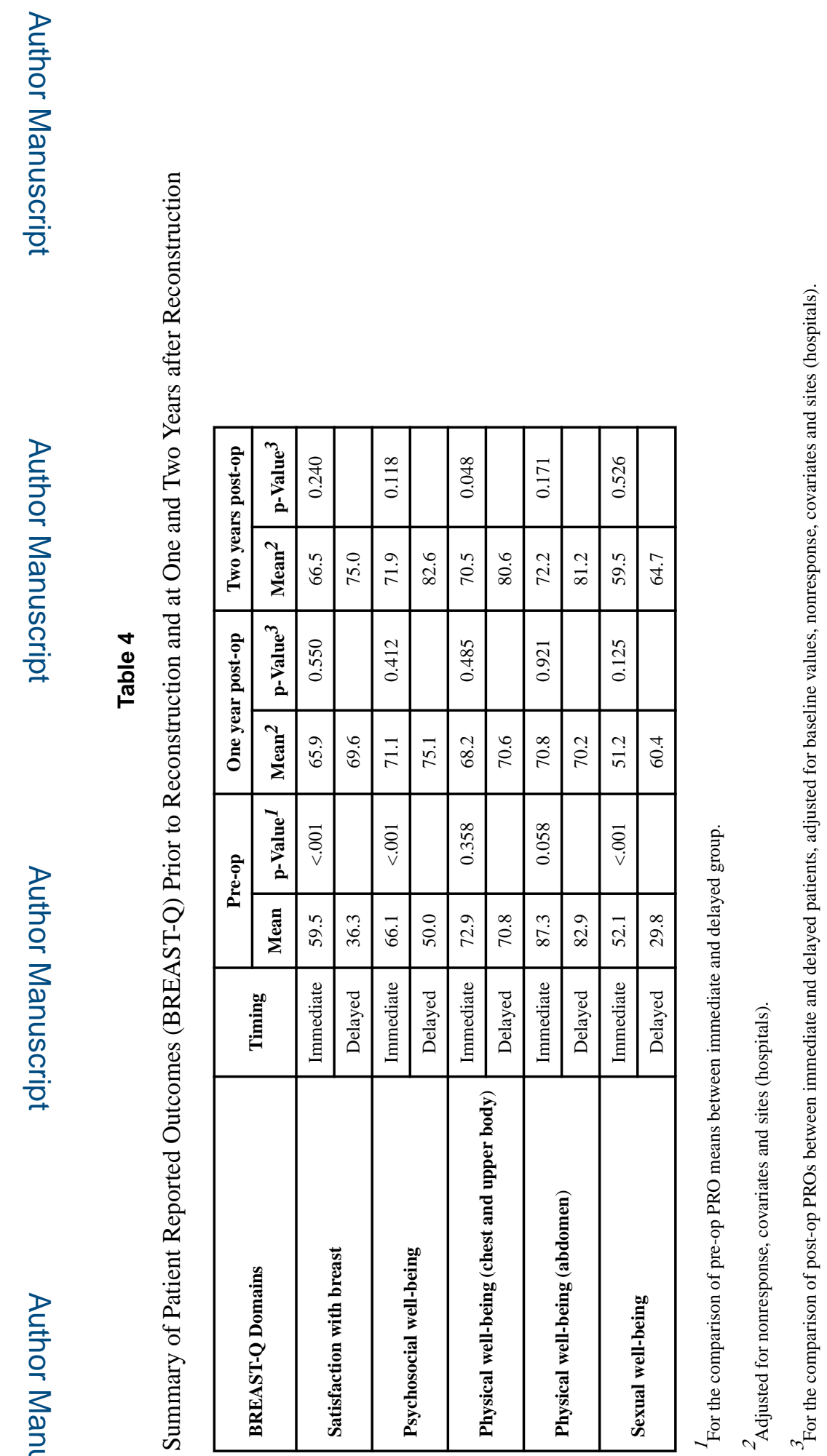

Plast Reconstr Surg. Author manuscript; available in PMC 2018 June 01. 


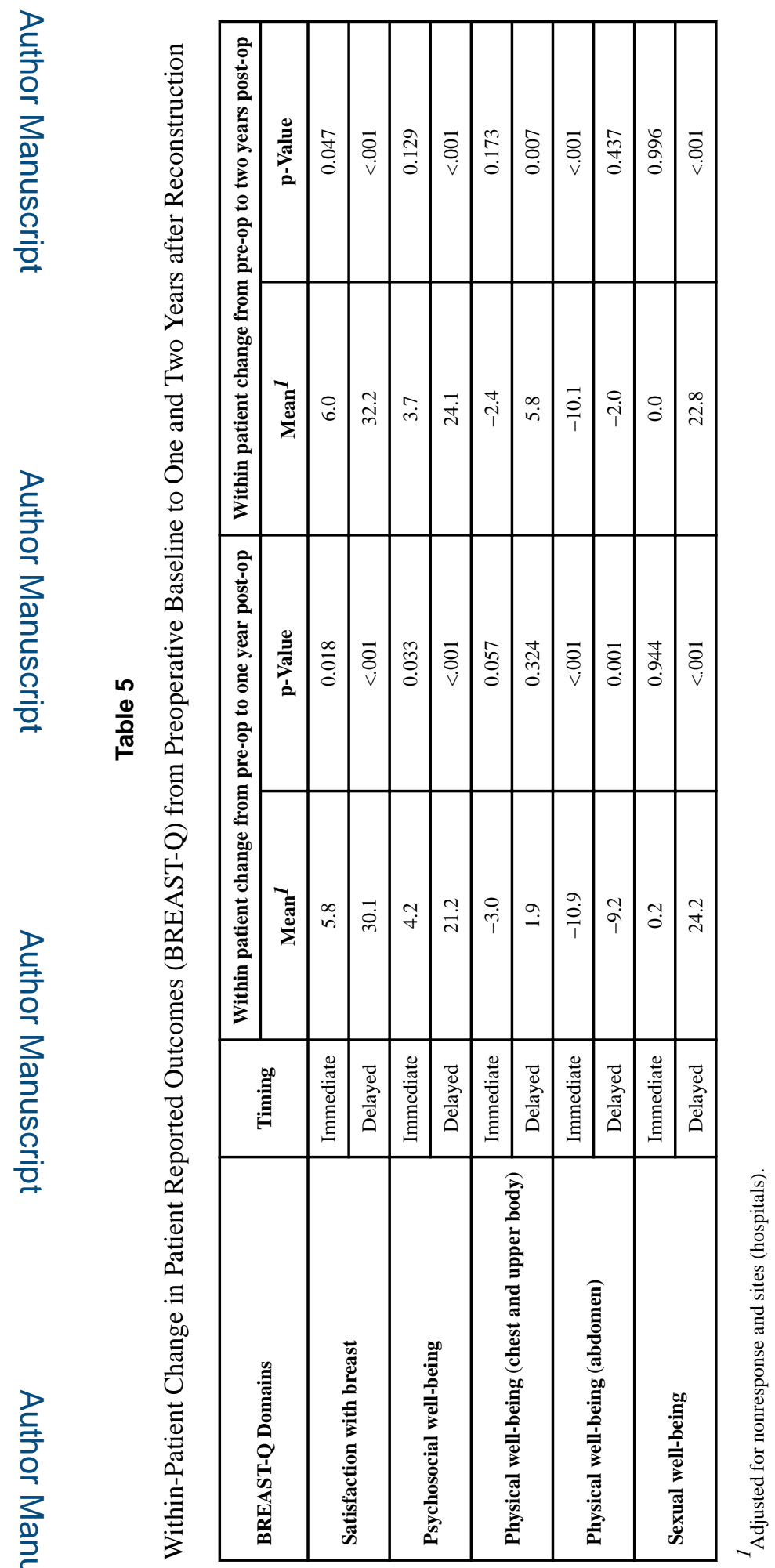

Plast Reconstr Surg. Author manuscript; available in PMC 2018 June 01. 